\title{
Paeoniflorin treatment regulates TLR4/NF-kB signaling, reduces cerebral oxidative stress and improves white matter integrity in neonatal hypoxic brain injury
}

\author{
Fan Yang ${ }^{1, \#}$, Ya Li $^{2,3,4, \#}$, Xun Sheng ${ }^{5}$, and Yu Liu ${ }^{6, *}$ \\ ${ }^{1}$ Department of Clinical Nutrition, The First People's Hospital of Yunnan Province, The Affiliated Hospital of Kunming University of Science and Technology, ${ }^{2}$ De- \\ partment of Clinical Laboratory, The First Affiliated Hospital of Kunming Medical University, ${ }^{3}$ Yunnan Institute of Laboratory Diagnosis, ${ }^{4}$ Yunnan Key Labora- \\ tory of Laboratory Medicine, ${ }^{5}$ School of Stomatology, Kunming Medical University, ${ }^{6}$ Department of Pharmacy, The First People's Hospital of Yunnan Province, \\ The Affiliated Hospital of Kunming University of Science and Technology, Kunming 650032, Yunnan, China
}

\section{ARTICLE INFO}

Received December 18, 2019

Revised April 14, 2020

Accepted April 14, 2020

*Correspondence

Yu Liu

E-mail:chubashi4@163.com

Key Words

Brain injury

Hypoxia

Neuroinflammation

Paeoniflorin

TLR4/NF- $\mathrm{B}$ signaling

\#These authors contributed equally to this work.

\begin{abstract}
Neonatal hypoxia/ischemia $(\mathrm{H} / \mathrm{l})$, injures white matter, results in neuronal loss, disturbs myelin formation, and neural network development. Neuroinflammation and oxidative stress have been reported in neonatal hypoxic brain injuries. We investigated whether Paeoniflorin treatment reduced $\mathrm{H} / \mathrm{l}$-induced inflammation and oxidative stress and improved white matter integrity in a neonatal rodent model. Seven-day old Sprague-Dawley pups were exposed to H/l. Paeoniflorin $(6.25,12.5$, or $25 \mathrm{mg} / \mathrm{kg}$ body weight) was administered every day via oral gavage from postpartum day 3 (P3) to P14, and an hour before induction of H/l. Pups were sacrificed 24 $h$ (P8) and 72 h (P10) following H/l. Paeoniflorin reduced the apoptosis of neurons and attenuated cerebral infarct volume. Elevated expression of cleaved caspase-3 and Bad were regulated. Paeoniflorin decreased oxidative stress by lowering levels of malondialdehyde and reactive oxygen species generation and while, and it enhanced glutathione content. Microglial activation and the TLR4/NF- $\kappa$ B signaling were significantly down-regulated. The degree of inflammatory mediators (interleukin $1 \beta$ and tumor necrosis factor- $\alpha$ ) were reduced. Paeoniflorin markedly prevented white matter injury via improving expression of myelin binding protein and increasing 01-positive olidgodendrocyte and O4-positive oligodendrocyte counts. The present investigation demonstrates the potent protective efficiency of paeoniflorin supplementation against $\mathrm{H} / \mathrm{l}$-induced brain injury by effectually preventing neuronal loss, microglial activation, and white matter injury via reducing oxidative stress and inflammatory pathways.
\end{abstract}

\section{INTRODUCTION}

Hypoxia/ischemia (H/I) induced brain injury due to lack or insufficient supply of glucose and oxygen to the brain is leading causes of neonatal morbidity and mortality with a higher occurrence rate of 2-6 per 1,000 births [1]. Neonatal H/I results in white matter injury, neuronal cell loss, impaired neuronal function due to failure of neural network subsequently leading to neurological impairments [2,3] as motor and cognitive disabilities, epilepsy, and autonomic dysfunction [4-6]. White matter is found to be highly vulnerable to injury following $\mathrm{H} / \mathrm{I}$ insult. H/I-induced loss of oligodendroglia, axonal damage, and impaired myelin formation have been reported in the pathogenesis of cerebral palsy and neurobehavioral deficits [7-10].

OPCs of the developing brain are predominantly liable to $\mathrm{H} / \mathrm{I}$ insults $[11,12]$. Loss of early OPCs and failure to differentiate to

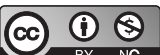

This is an Open Access article distributed under the terms of the Creative Commons Attribution Non-Commercial License, which permits unrestricted non-commercial use, distribution, and reproduction in any medium, provided the original work is properly cited. Copyright @ Korean J Physiol Pharmacol, pISSN 1226-4512, elSSN 2093-3827
Author contributions: F.Y. and Y.L. had equally contributed to this work and performed all activities relating to this study. F.Y., Y.L., X.S., and Y.L., designed the study and performed experiments and analysed the data and prepared this manuscript. 
mature OPCs disrupt myelination in the immature brain [12]. Developing brain is extremely susceptible to oxidative stress due to increased rate of oxygen utilization and low levels of endogenous antioxidant defense and high amounts of fatty acids $[13,14]$. Studies have suggested oxidative stress significantly contributes to the loss of early OPCs $[12,15]$.

Neuroinflammatory responses, characterized by activation of microglial cells, have been observed in neonatal hypoxic brain injuries [16,17]. Accumulating experimental data reveals that neuroinflammatory processes are critically involved in H/I-induced loss of early OPCs in developing brain [18-20]. The microglial cells are involved in the regulation of proliferation of neurons and oligodendrocytes [21,22]. Toll-like receptor 4 (TLR4) is expressed on microglia and mediates neuroinflammatory diseases [23]. Increased expression of TLR4 in microglia following hypoxic insult has also been reported in vitro [21]. Pro-inflammatory cytokines such as interleukin 1 (IL-1), IL-6 and tumor necrosis factor-alpha (TNF- $\alpha$ ) are generated by activated microglial cells. These proinflammatory cytokines are regarded as critical players in H/I-induced white matter damage in neonatal brain $[24,25]$. Excessive production of these cytokines has been reported to disrupt myelin formation, and also contribute to the loss of OPCs $[18,26]$. Thus, strategies that prevent/or reduce microglial activation and neuroinflammatory process and oxidative stress can prevent the loss of OPCs and aid in restoration of white matter integrity and brain development (Supplementary Fig. 1).

Paeoniflorin, monoterpene glucoside, is one of the primary bioactive compounds of the plant, Paeonia lactiflora. Paeoniflorin is reported to possess anti-cancer, immunomodulatory and neuroprotective effects [27-30]. In this investigation, we assessed the effects of systemic administration of Paeoniflorin in $\mathrm{H} / \mathrm{I}$ induced neonatal rodents.

\section{METHODS}

\section{Chemicals}

Isoflurane and paeoniflorin was obtained from Sigma-Aldrich, St. Louis, MO, USA. Antibodies against cleaved caspase-3, TLR4, TNF- $\alpha$, Bad, Bcl-2, $\beta$-actin and hypoxia-inducible factor- 1 alpha (HIF-1 $\alpha$ ) (Cell Signaling Technology, Beverly, MA, USA). For

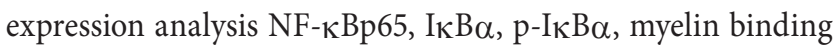
protein (MBP) (Santa Cruz Biotechnology, Santa Cruz, CA, USA), were utilized. Most other reagents and chemicals were purchased from Sigma-Aldrich, St. Louis, MO, USA indicated otherwise.

\section{Animal grouping and study design}

Female, pregnant Sprague Dawley rats $(\mathrm{n}=25)$ were obtained from the Institution Animal breeding center and were kept separately in sterile polypropylene rat cages under controlled animal house conditions (temperature $22^{\circ} \mathrm{C}-23^{\circ} \mathrm{C}$; relative humidity $55 \%-60 \% ; 12 \mathrm{~h} / 12 \mathrm{~h}$ day-night cycle). The rats were strictly observed for pups to be born and the day of birth was noted as postnatal day $0(\mathrm{P} 0)$. The experimental design and the procedures were endorsed by the Institutional ethical committee, and care and handling of the animals were in strict adherence to the guidelines issued by the National Institutes of Health on the care and use of animals [31].

P3 pups were randomly assigned to study groups (6 groups; $n$ = 24/group). Group I - control; Group II - H/I control; Group III to $\mathrm{V}-\mathrm{H} / \mathrm{I}$ induced and treated with paeoniflorin at $6.25 \mathrm{mg} / \mathrm{kg}$ body weight (b.wt), $12.5 \mathrm{mg} / \mathrm{kg}$ b.wt and $25 \mathrm{mg} / \mathrm{kg}$ b.wt respectively. Group VI pups were not exposed to $\mathrm{H} / \mathrm{I}$ insult but were treated with $25 \mathrm{mg} / \mathrm{kg}$ b.wt paeoniflorin.

$\mathrm{H} / \mathrm{I}$ was induced in P7 pups as described earlier by Rice et al. [32]. In brief, the P7 pups for induction were exposed to $3 \%$ isoflurane anaesthesia and for maintenance $1.5 \%$ isoflurane was used. The left common carotid artery was separated carefully and ligated twice with 6-0 surgical silk to block the flow of blood. The pups were allowed to recover for $2 \mathrm{~h}$ and were subjected to oxygen $(8 \%)$ in nitrogen gas mixture in a humidified chamber. The rats were maintained at $37^{\circ} \mathrm{C}$ by heating blanket that was thermostatically controlled. After hypoxia induction, the pups were allowed to breathe normal air for 5 to $10 \mathrm{~min}$, following which the pups were returned to their dams.

P3 pups were administered paeoniflorin $(6.25,12.5,25 \mathrm{mg} / \mathrm{kg}$ b.wt), orally via gavage from day P3 and extended till P14. Paeoniflorin was administered an hour before $\mathrm{H} / \mathrm{I}$ induction to the pups on P7. The dosage used was selected based on the results obtained by screening various doses of paeoniflorin ( $1 \mathrm{mg} / \mathrm{kg}$ to $100 \mathrm{mg} / \mathrm{kg}$ b.wt) at our laboratory. We received no significant changes in the vital parameters and were found not to exert any cytotoxic effects (data not included).

The rat pups were sacrificed on P8 ( $n=6 /$ group), P10 ( $n=6 /$ group) and on P14 ( $\mathrm{n}=6$ /group) under isoflurane anaesthesia by transcardial perfusion of saline-heparin tailed by ice-cold paraformaldehyde solution in 0.1 M PBS. Brains were excised immediately and used for analysis.

\section{Neurobehavioral deficit evaluation}

Neurobehavioral deficits were assessed in H/I induced rats on P8, P14 and P21. The extent of the neurological deficit was graded based on parameters as - symmetry of movements, symmetry of the forelimbs, spontaneous activity, climbing, touch response, and vibrissae touch response. The behaviour of animals was graded on a scale between $0-4$. The animals were scored as: 0 no deficit (normal); 1 - mild deficit; 2 - moderate deficit; 3 - severe deficit; and 4 - very severe deficit [33,34]. 


\section{Determination of extent of brain infarction}

Tissue viability and infarct size was measured following $24 \mathrm{~h}$ after H/I on P8 and P14 day. Brain tissue sections of $5 \mu \mathrm{m}$ thickness ( $\mathrm{n}=6$ /group; $\mathrm{n}=4 / \mathrm{animal}$ ) were cut at the level of interaural distance $5.40 \mathrm{~mm}$ and bregma $3.60 \mathrm{~mm}$. The sections were embedded in paraffin were incubated with cresyl violet stain. Tissue sections were visualised (Carl Zeiss Stemi 2000-C stereomicroscope; Zeiss, Oberkochen, Germany) and the infarcted location was measured with NIH ImageJ software (Version1.42; National Institutes of Health, Bethesda, MD, USA). The infarcted region was unstained, while normal areas appeared stained with cresyl violet. The extent of infarction was determined as follows infarct area $(\%)=([\mathrm{C}-\mathrm{I}] / \mathrm{C}) \times 100$; C - mean of the contralateral area and $\mathrm{I}$ - mean value of the ipsilateral area.

\section{Determination of neuronal apoptosis}

Staining with terminal transferase-mediated dUTP nickend-labeling (TUNEL) was done to evaluate neuronal apoptosis following $\mathrm{H} / \mathrm{I}$. Sections of tissues measuring about $5 \mu$ m thickness ( $n=6 /$ group) were treated as per the instructions specified (DeadEnd fluorometric TUNEL system kit; Promega, Madision, WI, USA) and were analysed for apoptotic cells by NIS-Elements BR imaging processing and analysis software (Nikon Corporation, Tokyo, Japan).

\section{Immunohistochemical study}

Immunohistochemical examination was done to determine the effects of H/I on myelination in H/I induced pups. The assessments were done on P8 and P14. The excised brains that were post-fixed and equilibrated in 30\% sucrose in $0.1 \mathrm{M}$ PBS were used for analysis. Coronal sections ( $5 \mu \mathrm{m}$ thickness) sliced at interaural distance $5.40 \mathrm{~mm}$ and bregma $-3.60 \mathrm{~mm}$ level using microtome (Leica 1325; Leica Biosystems, Nussloch, Germany). The sections were cleaned with PBS and then treated with $1 \%$ $\mathrm{H}_{2} \mathrm{O}_{2}$ in PBS and $0.25 \%$ Triton X-100 in PBS (blocking solution) to exclude any activity of endogenous peroxidase. The sections were cleaned with PBS and incubated with specific primary antibodies against MBP, pre-myelinating oligodendrocytes (anti-O4; clone 81; Millipore, Billerica, MA, USA), immature oligodendrocytes (anti-O1; clone 59; Millipore) and incubated at $4^{\circ} \mathrm{C}$ overnight. Following incubation with primary antibodies, the sections were cleaned thrice with PBS and treated with horse-radish peroxidase tagged secondary antibodies for $1 \mathrm{~h}$, treated with diaminobenzidine (DAB) and hematoxylin counterstained. The tissue sections were then dehydrated in ethanol and treated with xylene. The immunolabeled tissue sections were visualised and analysed using a light microscope (Olympus BX 50; Olympus, Tokyo, Japan).

Microglial activation was determined by assessing the expression of ionized calcium binding adaptor molecule 1 (Iba-1) as previously mentioned by Arteaga et al. [38]. The brain tissue sections
$(60 \mu \mathrm{m})$ thickness were blocked for peroxidase activity and then treated with anti-Iba- 1 primary antibody at $4^{\circ} \mathrm{C}$ (Abcam, Cambridge, UK) overnight. The segments were cleaned twice with PBS and incubated further with secondary antibody conjugated with Alexa 488 (Abcam) and then counterstained with DAPI. The tissue sections were examined using a Confocal Microscope (Olympus Fluoview FV500; Olympus).

\section{Immunoblotting}

Excised brain tissues ( $\mathrm{n}=6$ 6/group) were blended using cell lysis buffer from Cell Signaling Technology, USA (20 mM Tris-HCl [pH 7.5], $1 \mathrm{mM}$ EGTA, 1\% Triton, $2.5 \mathrm{mM}$ sodium pyrophosphate, $150 \mathrm{mM} \mathrm{NaCl}, 1 \mathrm{mM} \mathrm{Na}_{3} \mathrm{VO}_{4}, 1 \mu \mathrm{g} / \mathrm{ml}$ leupeptin, $1 \mathrm{mM}$ $\mathrm{Na}_{2}$ EDTA, $1 \mathrm{mM}$ beta-glycerophosphate). The whole cell extracts obtained were subjected to centrifugation (3,000 rpm; $15 \mathrm{~min}$ ) at $4^{\circ} \mathrm{C}$. Supernatant collected was used for analysis. Cytosol and nuclear fractions were separated from the whole cell homogenate using ReadyPrep Protein Extraction Kit (Cytoplasmic/Nuclear) from Bio-Rad (Hercules, CA, USA). Total protein content of the whole cell extracts and in cytosol and nuclear fractions were quantified using kits from Thermo Fischer Scientific (Waltham, MA, USA). For Western blot analysis 60-80 $\mu$ g amount of protein sample ( $\mathrm{n}=6$ /group) were loaded on SDS-PAGE $(10 \%-15 \%)$ gels and were electrophoresed. The separated protein bands were blot transferred on to polyvinylidinene fluoride (PVDF; Thermo Fischer Scientific) and the membranes were blocked in 5\% nonfat dry milk in 1x TBST to exclude any endogenous peroxidase activity. After washing with TBST, the PVDF membranes were incubated nightlong at $4^{\circ} \mathrm{C}$ with the primary antibodies. The membranes were cleaned using TBST and treated with secondary antibody (Horse radish peroxidase-conjugated; 1:2,000; Santa Cruz Biotechnology) at room temperature for $60 \mathrm{~min}$. After incubating with secondary antibodies, the membranes were cleaned again with TBST and the bands were observed using enhanced chemiluminescence system (Millipore). The positive bands obtained were scanned and analysed using Image J software (Supersignal, Pierce, IL, USA).

\section{ELISA}

Concentrations of pro-inflammatory mediators - IL-1 $\beta$ and TNF- $\alpha$ in the brain tissues post $\mathrm{H} / \mathrm{I}$ insult were determined by ELISA. The fore brain tissues were homogenised in $0.1 \mathrm{M}$ ice-cold Phosphate buffer and centrifuged. The supernatant was used for analysis of total protein content and for TNF- $\alpha$ and IL-1 $\beta$ levels using kits from RD systems (Minneapolis, MN, USA).

\section{Determination of ROS}

Brain tissue samples $(n=6)$ were homogenized from each treatment group with 1:10 (w/v) PBS on ice and centrifuged $(3,000$ 
rpm; $15 \mathrm{~min}, 4^{\circ} \mathrm{C}$ ). Accumulated supernatant was used for determination of ROS generation, lipid peroxidation and glutathione (GSH) levels. Total quantity of protein in supernatant was found using Bradford protein assay kit (Bio-Rad). Levels of ROS in the brain tissues on P14 was detected using in vitro ROS/RNS assay kit (OxiSelect) from Cell Bio-Labs Inc. Dichlorodihydrofluorescin DiOxyQ (DCFH-DiOxyQ), a fluorogenic probe specific to ROS/ RNS was employed. The fluorescence intensity is measured using Synergy 2 Multi-function Microplate Reader.

\section{Assay of malondialdehyde and glutathione levels}

Lipid peroxidation levels of the H/I-induced brain was determined as malondialdehyde (MDA) content. MDA and GSH levels were detected by means of assay kits from Sigma-Aldrich, according to the manufacturer's instructions.

\section{Statistical analysis}

The results of the investigation were statistically analysed using SPSS software (Version 22.0; IBM Co., Armonk, NY, USA). The obtained data were subjected to One-way analysis of variance (ANOVA) and Duncan's Multiple Range Test (DMRT). $\mathrm{p}<0.05$ was regarded significant.

\section{RESULTS}

\section{Paeoniflorin treatment attenuated neurobehavioral deficits}

The P8, P14 and P21 rats that were exposed to hypoxic insult on P7 were assessed for behavioural responses and neuromuscular coordination. The $\mathrm{H} / \mathrm{I}$ induced rats exhibited difficulties to walk and to move around indicating neurological deficits (Fig. 1).
The flexibility of the left limbs was found to be reduced and the rats struggled to respond to the test stimulus. The neurological deficits were observed to be substantively $(p<0.05)$ reduced in animals that were treated with paeoniflorin at $6.25,12.5$ and 50 $\mathrm{mg}$ doses. Furthermore, on day P21 rats treated with paeoniflorin noticeably $(\mathrm{p}<0.05)$ exhibited development in the neuro-behavioural responses and in muscular coordination vs. paeoniflorin treated rats at P8 and P14. Further, the behaviour of the group 6 animals that were administered with paeoniflorin at $25 \mathrm{mg} / \mathrm{kg}$ dosage and not subjected to hypoxic insult did not exhibit any neurological deficits. The behaviour of the rats was similar to that of normal control.

\section{Paeoniflorin reduced infarct area and $\mathrm{H} / \mathrm{l}$-induced brain injury}

Infarct area following $\mathrm{H} / \mathrm{I}$ was determined by cresyl violet staining. Infarcted regions appeared as unstained regions vs. normal regions stained with cresyl violet. The ischemic areas were observed predominantly in the striatum and in the fronto-parietal cortex regions (Fig. 2A, B). Pre- treatment with paeoniflorin at $6.25,12.5$ and $25 \mathrm{mg}$ doses resulted in a substantially $(\mathrm{p}<0.05)$ reduced infarct volume following H/I (Fig. 2A, B). Nevertheless, supplementation of $25 \mathrm{mg}$ dose more expressively $(\mathrm{p}<0.05)$ decreased cerebral infarct size in comparison to lower doses. In P8 rats, the infarct volume decreased from $68.15 \%$ to $15.72 \%$ and in P10 rats the infarct volume reduced to $10.08 \%$ and in P14 rats the infarct volume reduced to $5.79 \%$ with paeoniflorin treatment at $25 \mathrm{mg}$. Further, group 6 rats that were treated with paeoniflorin at $25 \mathrm{mg}$ alone did not exhibit any neuronal injury. Also, interestingly, irrespective of the dosage given, the infarct size was significantly reduced in rats.

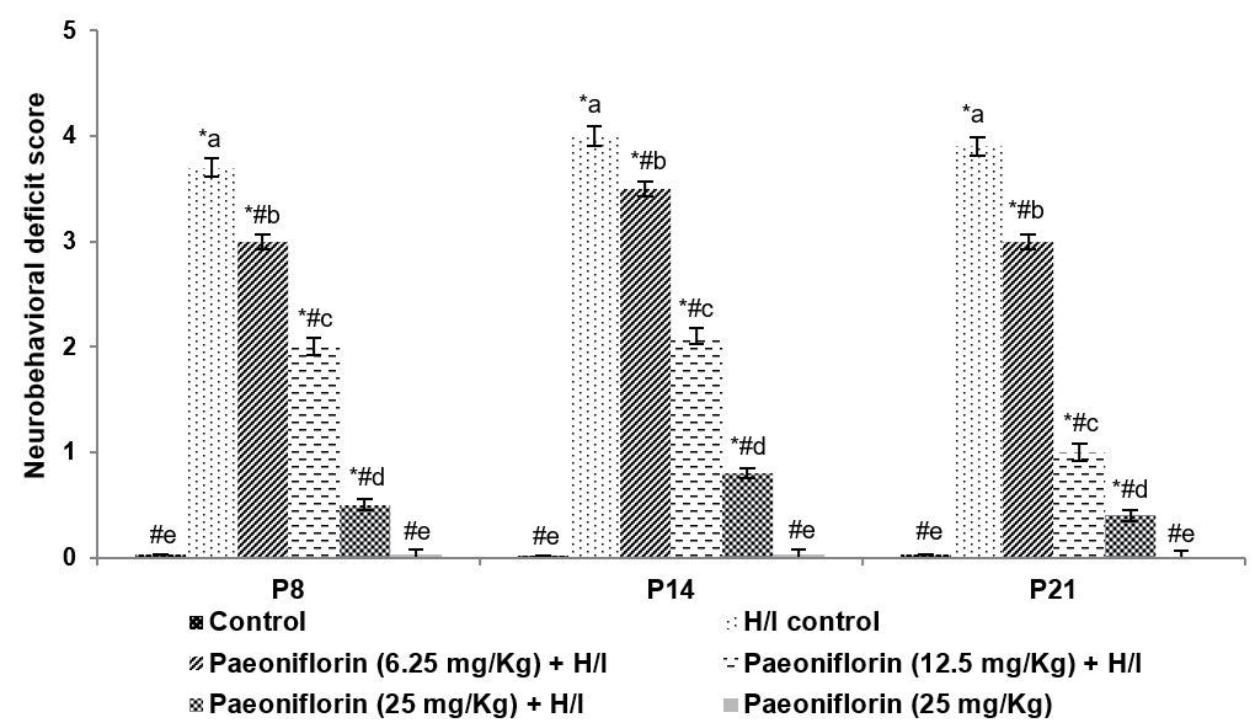

Korean J Physiol Pharmacol 2021;25(2):97-109
Fig. 1. Neurobehavioral deficits following hypoxic ischemia. Values are represented as mean \pm standard deviation, $n=6 . p<0.05$ as determined by one-way ANOVA followed by DMRT analysis. $\mathrm{H} / \mathrm{I}$, hypoxia/ischemia; $\mathrm{P}$, postpartum day. *Represents $p<0.05$ vs. control; "represents $\mathrm{p}<0.05$ vs. H/I control. ${ }^{\mathrm{a} e \mathrm{e}}$ Represents mean values from different experimental groups that differ from each other at $p<0.05$. 
A
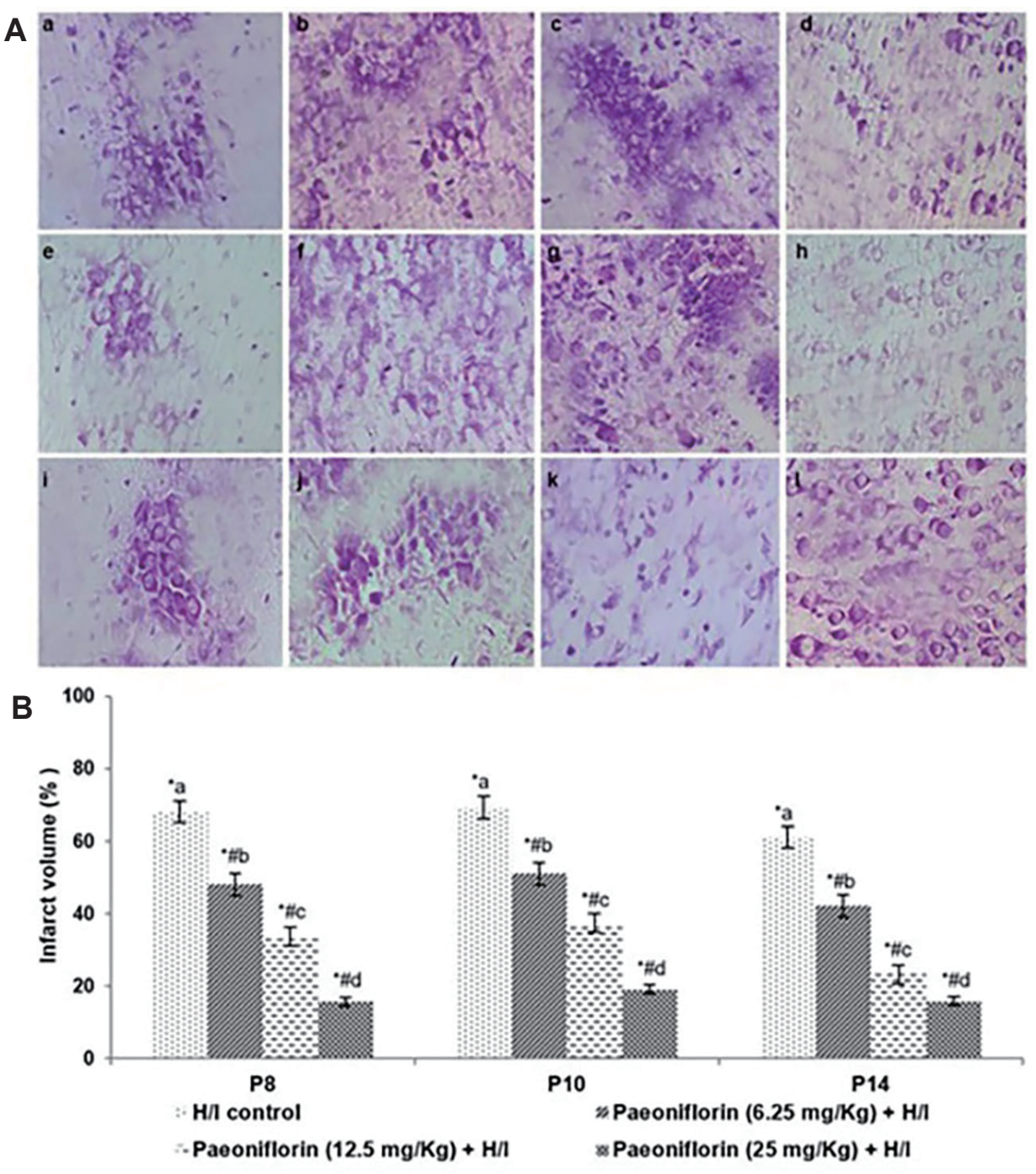

Fig. 2. Paeoniflorin reduced cerebral infarct area. Cresyl violet staining $(\times 100)(A)$ and expressed infract volume (B). Values are represented as mean \pm standard deviation, $n=6 . p<0.05$ as determined by one-way ANOVA followed by DMRT analysis. H/l, hypoxia/ischemia; P, postpartum day. ${ }^{*}$ Represents $p<0.05$

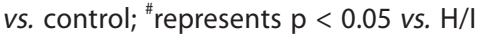
control. ${ }^{a-d}$ Represents mean values from different experimental groups that differ from each other at $p<0.05\left({ }^{a-d}\right.$ Control, ${ }^{\mathrm{e}-\mathrm{h}} \mathrm{H} / \mathrm{I}$ control, ${ }^{\text {i- }}$ paeoniflorin [25 mg/kg]).

\section{Paeoniflorin inhibited $\mathrm{H} / \mathrm{l}-$ induced neuronal apoptosis}

Neuroprotective effects of paeoniflorin pre-treatment was further evaluated by TUNEL assay. The data obtained illustrated that administration of paeoniflorin produced a significant $(\mathrm{p}<$ 0.05 ) decline in $\mathrm{H} / \mathrm{I}$-induced neuronal cell death (Fig. 3A, B). The apoptotic cell counts decreased from 149 cells $/ \mathrm{mm}^{2}$ in H/I control to 52 cells $/ \mathrm{mm}^{2}$ on paeoniflorin treatment at $25 \mathrm{mg} / \mathrm{kg}$ dose in P8 rats, 19 cells $/ \mathrm{mm}^{2}$ in P10 rats and 12 cells $/ \mathrm{mm}^{2}$ in P14 rats.

To evaluate further the neuroprotective effects of paeoniflorin treatment prior and post $\mathrm{H} / \mathrm{I}$ induction, the expression of the proteins associated with cell apoptosis were evaluated by Western blotting in P8 rats exposed to H/I on P7 (Fig. 4A, B). Up-regulated expression of Bad and Cleaved caspase- 3 were noticed in the $\mathrm{H} / \mathrm{I}$ control group vs. normal control. The expression of $\mathrm{Bcl}-2$, the anti-apoptotic protein was detected to be reduced in P8 rats. The enhanced expression of Bad and cleaved caspase- 3 observed could have contributed to increased apoptotic cell counts as noticed in TUNEL assay. Interestingly, while elevated expression of Bcl-2 was noticed on paeoniflorin treatment, decreased expres- sion of Bad and cleaved caspase- 3 vs. H/I control were observed (Fig. 4A, B). Bcl-2 expression increased to $66.3 \%, 78.14 \%$, and $85 \%$ on treatment with $6.25,12.5$, and $25 \mathrm{mg}$ paeoniflorin respectively. Cleaved caspase-3 expression decreased to $18.10 \%$ in H/I-induced rats treated with $25 \mathrm{mg}$ paeoniflorin. Modulation of apoptotic protein expression by paeoniflorin could have aided in reduced neuroapoptotic cell counts.

\section{Paeoniflorin reduces oxidative stress}

H/I-induced oxidative stress is well documented in H/I-induced brain injury [35]. ROS and lipid peroxidation levels in brain tissues were measured in P8 pups at $24 \mathrm{~h}$ following induction of $\mathrm{H} / \mathrm{I}$ and in $\mathrm{P} 10$ rats at $72 \mathrm{~h}$ post $\mathrm{H} / \mathrm{I}$ insult. A multi-fold increase in ROS and MDA levels following $\mathrm{H} / \mathrm{I}$ was observed (Fig. 5A, B). ROS generation was found to increase to $375.08 \%$ in $\mathrm{H} / \mathrm{I}$ control on P8 and to $407.08 \%$ in P10 rats vs. normal control group. MDA content was observed to raise to $21.30 \mathrm{nM} / \mathrm{mg}$ protein at $24 \mathrm{~h}$ and to $29.63 \mathrm{nM} / \mathrm{mg}$ protein at $72 \mathrm{~h}$ following $\mathrm{H} / \mathrm{I}$ insult vs. $1.17 \mathrm{nM} /$ $\mathrm{mg}$ protein in normal control. Interestingly, treatment with pae- 

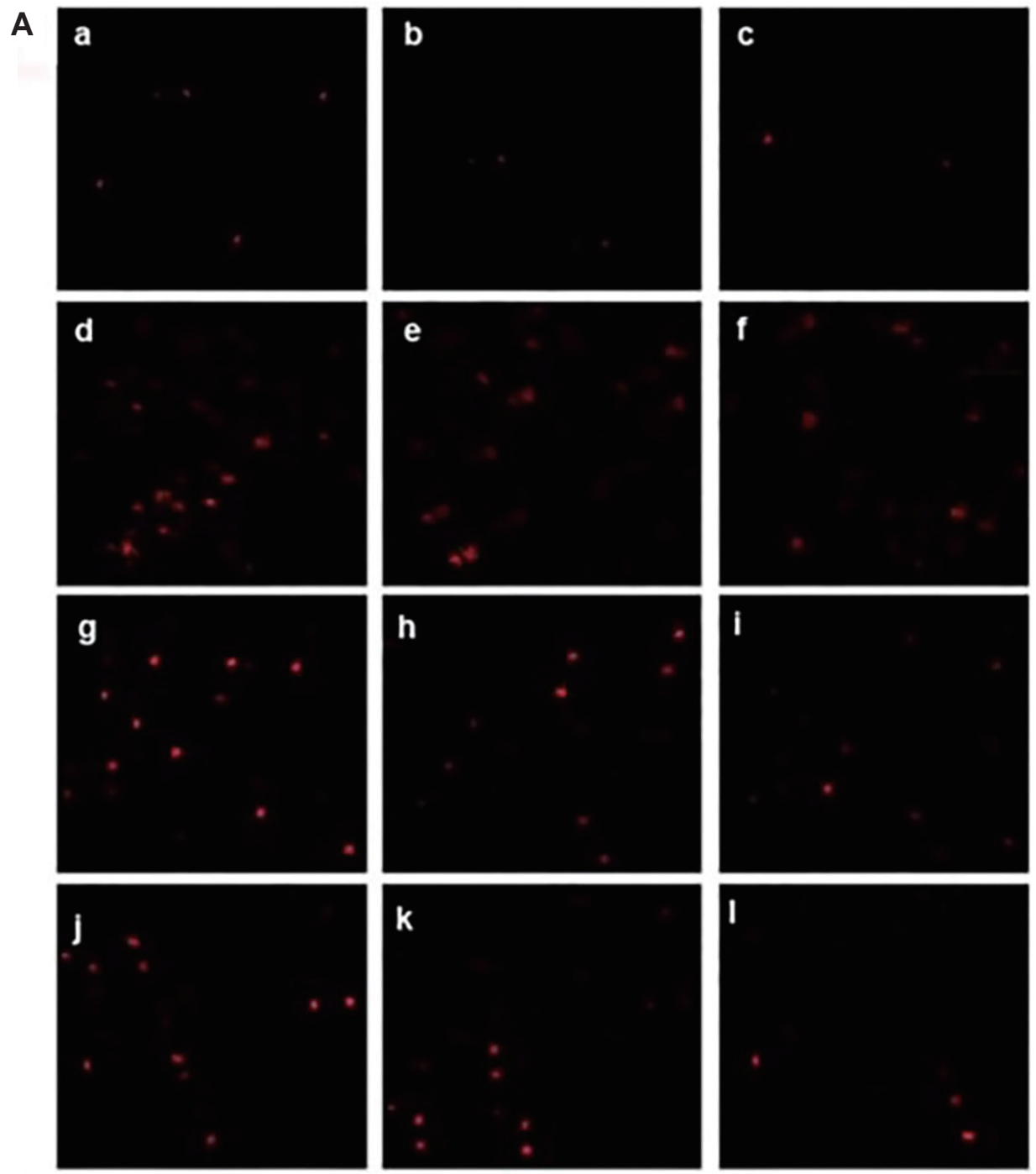

B

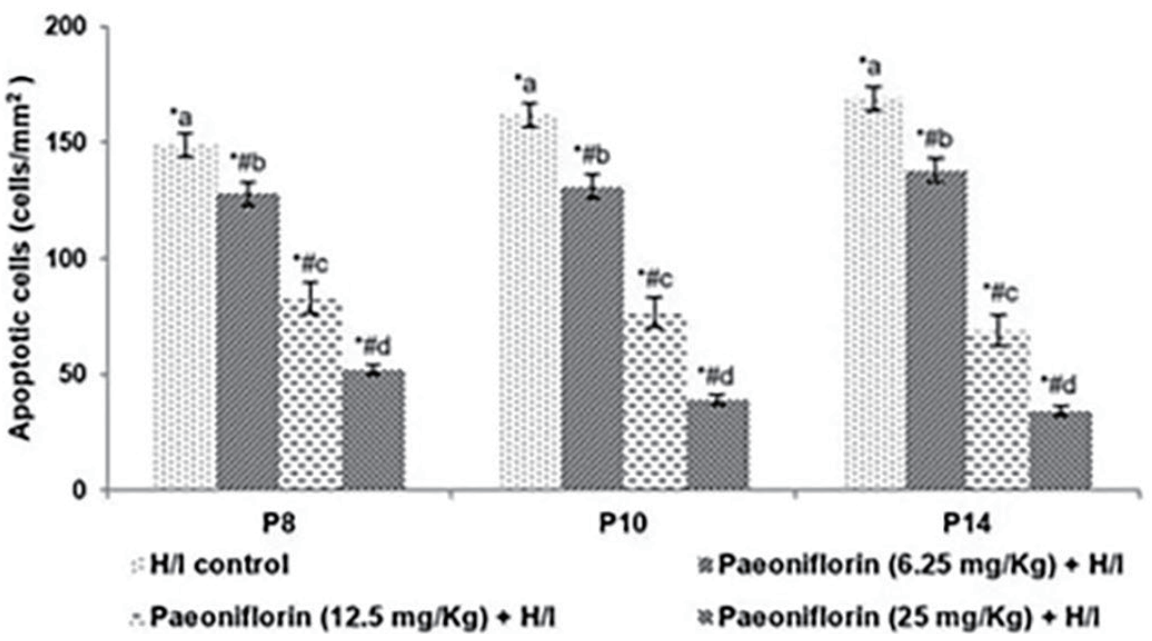

Fig. 3. Paeoniflorin reduced neuronal apoptosis. Tissue sections in TUNEL assay (A) and apoptotic cell count (B). Values are represented as mean \pm standard deviation, $n=6$. $p<0.05$ as determined by one-way ANOVA followed by DMRT analysis. H/l, hypoxia/ischemia; $\mathrm{P}$, postpartum day. ${ }^{*}$ Represents $p<0.05$ vs. control; " represents $\mathrm{p}<0.05$ vs. $\mathrm{H} / \mathrm{l}$ control. ${ }^{\mathrm{a}-\mathrm{d}}$ Represents mean values from different experimental groups that differ from each other at $p<0.05\left({ }^{a-c}\right.$ Control, ${ }^{d-f} \mathrm{H} / \mathrm{l}$ control, ${ }^{g-i}$ paeoniflorin [25 mg/kg] +

$\therefore$ Paeoniflorin (12.5 mg/Kg) $+\mathrm{H} /$

2 Paeoniflorin $(25 \mathrm{mg} / \mathrm{Kg})+\mathrm{H} / \mathrm{I}$ $\mathrm{H} / \mathrm{l},{ }^{\mathrm{j}-1}$ paeoniflorin $[25 \mathrm{mg} / \mathrm{kg}]$ ).

oniflorin at all the dosages tested decreased ROS and MDA levels. ROS generation decreased to $118.09 \%$ (P8) and $125.1 \%$ (P10) with $25 \mathrm{mg}$ treatment vs. $375.08 \%$ in H/I control. In line with ROS, MDA levels were also reduced on paeoniflorin treatment when compared to H/I control. MDA levels reduced to 8.12, 5.07, 2.1 $\mathrm{nM} / \mathrm{mg}$ protein in P8 rats on treatment with $6.25 \mathrm{mg}, 12.5 \mathrm{mg}$, and 25 paeoniflorin respectively.

GSH levels in H/I control rats were found to be reduced ( $\mathrm{p}<$ 0.05) in H/I-induced P8 rat pups (Fig. 5C). Twenty four hours post $\mathrm{H} / \mathrm{I}$ induction, GSH content decreased to $13.76 \mathrm{nM} / \mathrm{mg}$ protein in $\mathrm{H} / \mathrm{I}$ control vs. $38.19 \mathrm{nM} / \mathrm{mg}$ protein in normal control group. Supplementation of paeoniflorin to pups from P3 resulted in a 


\section{A}

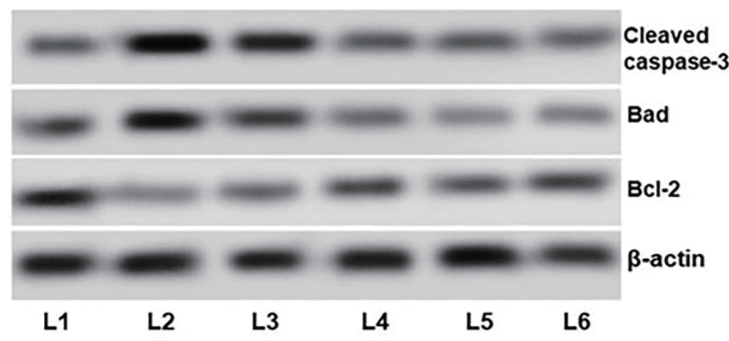

B

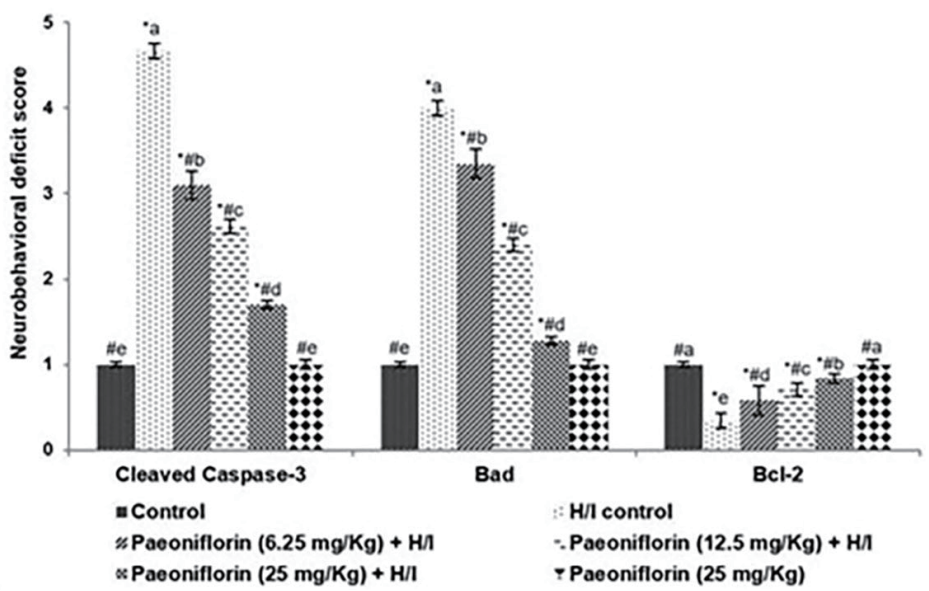

Fig. 4. Paeoniflorin regulated the expression of apoptotic proteins $24 \mathrm{~h}$ following hypoxic ischemia in P7 pups. (A) Western blotting and protein expression (B). Values are represented as mean \pm standard deviation, $n=6 . p<0.05$ as determined by one-way ANOVA followed by DMRT analysis. H/l, hypoxia/ischemia; P, postpartum day. ${ }^{*}$ Represents $\mathrm{p}<0.05 \mathrm{vs}$. control; ${ }^{\#}$ represents $\mathrm{p}<0.05 \mathrm{vs}$. H/I control. ${ }^{\mathrm{a}-\mathrm{e}}$ Represents mean values from different experimental groups that differ from each other at $\mathrm{p}<0.05$ (L1, control; L2, H/l control; L3, paeoniflorin [6.25 mg/kg] + H/l; L4, paeoniflorin [12.5 $\mathrm{mg} / \mathrm{kg}]+\mathrm{H} / \mathrm{l} ; \mathrm{L} 5$, paeoniflorin $[25 \mathrm{mg} / \mathrm{kg}]+\mathrm{H} / \mathrm{l} ; \mathrm{L} 6$, paeoniflorin $(25 \mathrm{mg} / \mathrm{kg}])$.

markedly raised GSH content in the brain tissues. The levels increased to $15.37 \mathrm{nM} / \mathrm{mg}$ protein, $29.28 \mathrm{nM} / \mathrm{mg}$ protein and 40.33 $\mathrm{nM} / \mathrm{mg}$ protein on treatment with $6.25 \mathrm{mg}, 12.5 \mathrm{mg}$, and 25 paeoniflorin respectively. P10 rats exposed to $\mathrm{H} / \mathrm{I}$ insult and treated with paeoniflorin at $25 \mathrm{mg}$ also exhibited a significant increase in GSH levels. Further, group 6 rats that were treated with $25 \mathrm{mg}$ paeoniflorin alone presented GSH levels of $39.78 \mathrm{nM} / \mathrm{mg}$ protein (P8 rats) and $42.74 \mathrm{nM} / \mathrm{mg}$ protein (P10 rats). The levels were comparable to that of normal control.

\section{Paeoniflorin reduced microglial activation and TLR4/ NF- $\mathrm{kB}$ signaling}

Activation of microglia were assessed by determining the expression of the macrophage marker Iba-1. H/I-induction resulted in a significant $(\mathrm{p}<0.05)$ rise in Iba-1-postive cells (Fig. 6A). Activated microglial cells were observed in the dentate gyrus and in the hippocampal CA 1 areas in the H/I control animals vs. normal controls. In contrast, Iba-1 expression levels were noticed to be remarkably decreased in P8 and in P10 pups treated with paeoniflorin at all the 3 tested doses compared to $\mathrm{H} / \mathrm{I}$ control.

TLR4 levels were seen to increase multi-fold post H/I to $205.10 \%$ in P8 and to $280.26 \%$ in P10. HIF-1 $\alpha$ levels were elevated to $190 \%$ in P8 and to $289.1 \%$ at P10. The up-regulated expression of TLR4 and HIF- $1 \alpha$ observed following $24 \mathrm{~h}$ and $72 \mathrm{~h}$ of $\mathrm{H} / \mathrm{I}$ induction were down-regulated significantly $(\mathrm{p}<0.05)$ in rats supplemented with paeoniflorin (Fig. 6B). TLR4 and HIF-1 $\alpha$ expression reduced to $129 \%$ and $115.2 \%$ respectively in P8 rats administrated with $25 \mathrm{mg}$ Paeoniflorin. These observations suggest that paeoniflorin effectively reduced microglial activation.

$\mathrm{NF}-\kappa \mathrm{B}$ signaling is known to be activated under hypoxic conditions [36]. H/I induction in P7 rats caused a markedly enhanced $(\mathrm{p}<0.05)$ nuclear NF- $\kappa \mathrm{B}(\mathrm{p} 65)$ expression with substantially $(\mathrm{p}<0.05)$ lower cytosolic levels of NF- $\kappa B$ (p65) (Fig. 7). The observations indicate activation of NF- $\kappa$ B. Furthermore upregulated expression of TNF- $\alpha$, and levels of phosphorylation of the regulatory kinase-IKB $\alpha$ were noted both at $24 \mathrm{~h}$ and $72 \mathrm{~h}$ post $\mathrm{H} / \mathrm{I}$. However, we noticed a marked increase in nuclear NF$\kappa \mathrm{B}$ (p65) expression at $\mathrm{P} 10$ when compared at $24 \mathrm{~h}$. Paeoniflorin supplementation at all the 3 doses resulted in a significant suppression ( $\mathrm{p}<0.05$ ) of NF- $\mathrm{B}$ p 65 (nuclear fraction) expression $v$. $\mathrm{H} / \mathrm{I}$ control. $25 \mathrm{mg}$ dose of paeoniflorin significantly $(\mathrm{p}<0.05)$ reduced the expression of NF- $\mathrm{KB}$ p 65 in the nuclear fraction from $191.21 \%$ to $119.23 \%$ at P8 and from $235.10 \%$ to $139.27 \%$ at P10. Paeoniflorin at the tested doses of $6.25 \mathrm{mg} / \mathrm{kg}, 12.5 \mathrm{mg} / \mathrm{kg}$ and 25 $\mathrm{mg} / \mathrm{kg}$ down-regulated $\mathrm{p}-\mathrm{I}_{\kappa} \mathrm{B} \alpha$ expression vs. $\mathrm{H} / \mathrm{I}$ control group at both $\mathrm{P} 8$ and $\mathrm{P} 10$. These observations suggest the inhibit activation of NF- $\mathrm{KB}$ signaling by paeoniflorin.

Brain levels of proinflammatory cytokines - IL-1 $\beta$ and TNF- $\alpha$ at $24 \mathrm{~h}$ after $\mathrm{H} / \mathrm{I}$ were observed to be significantly raised $(\mathrm{p}<0.05)$ vs. normal control (Fig. 8). Paeoniflorin pre-treatment from P3 resulted in a significant drop in the concentration of IL-1 $\beta$ and TNF- $\alpha$.

\section{Paeoniflorin improved white matter integrity}

White matter integrity post $\mathrm{H} / \mathrm{I}$ insult was detected by calculating the density of MBP positive cells by immunohistochemical analysis. A significant reduction in MBP positive cell counts were observed at $24 \mathrm{~h}$ following H/I. MBP positive counts was noticed to be reduced by $29.12 \%$ at $24 \mathrm{~h}$ and $18.08 \%$ at $72 \mathrm{~h}$ post $\mathrm{H} / \mathrm{I}$ in the in the corpus callosum of $\mathrm{H} / \mathrm{I}$ control rats in comparison to normal control rats (Fig. 9). Prior treatment with paeoniflorin from P3 significantly $(\mathrm{p}<0.05)$ improved MBP counts from 29.12\% 

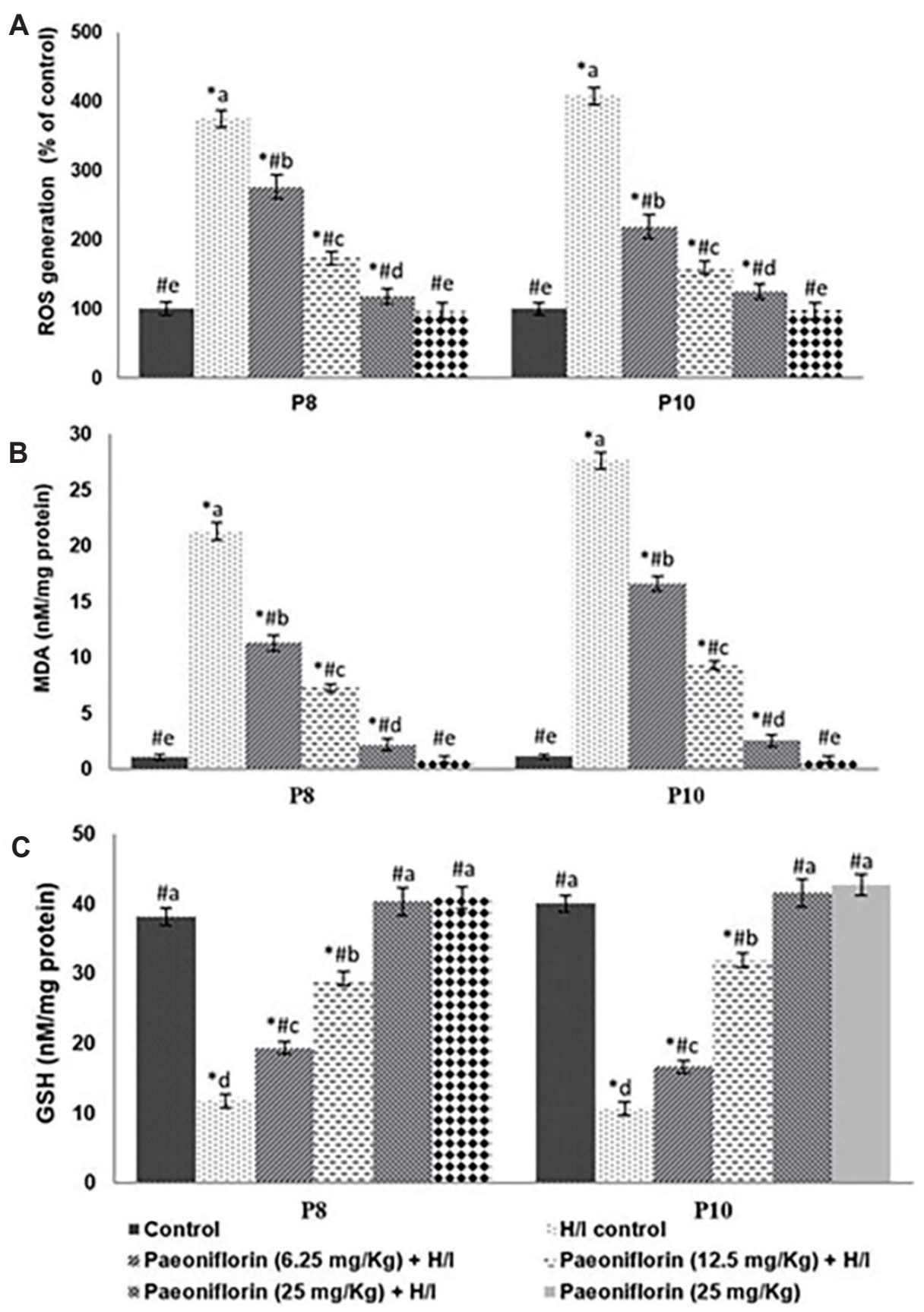

Fig. 5. Paeoniflorin reduces oxidative stress. Paeoniflorin reduced ROS generation following $\mathrm{H} / \mathrm{I}$ (A) MDA levels (B) and improved GSH levels (C). Values are represented as mean \pm standard deviation, $n=6 . p<0.05$ as determined by one-way ANOVA followed by DMRT analysis. ROS, reactive oxygen species; MDA, malondialdehyde; GSH, glutathione; H/l, hypoxia/ ischemia; P, postpartum day. ${ }^{*}$ Represents $\mathrm{p}<0.05$ vs. control; " represents $\mathrm{p}<0.05$ vs. $\mathrm{H} / \mathrm{I}$ control. ${ }^{\text {a-e }}$ Represents mean values from different experimental groups that differ from each other at $p<0.05$. to $37.24 \%, 49.33 \%$ and $68.79 \%$ with $6.25 \mathrm{mg}, 12.5 \mathrm{mg}$ and $25 \mathrm{mg}$ doses respectively at P8. Paeoniflorin supplementation at $25 \mathrm{mg}$ improved MBP counts to $71.23 \%$ at P10. However, paeoniflorin alone administered rats exhibited no significant difference in MBP-positive cell counts on P8 and P10.

OPCs proliferation and maturation are critical for myelination. We noticed a significant decrease in the O4-positive oligodendrocytes and O1-positive oligodendrocytes at $24 \mathrm{~h}$ and $72 \mathrm{~h}$ following $\mathrm{H} / \mathrm{I}$ insult in P8 and in P10 rat pups. Paeoniflorin treatment was found to effectively reduce the loss of OPCs (Fig. 9). In P8 pups, paeoniflorin at $25 \mathrm{mg}$ significantly $(\mathrm{p}<0.05)$ improved the counts of O4-positive oligodendrocytes to $89.67 \%$ from $16.14 \%$ in $\mathrm{H} / \mathrm{I}$ control and O1-positive counts to $93.10 \%$ vs. $18.34 \%$ in $\mathrm{H} / \mathrm{I}$ control group.
The results reveal that paeoniflorin effectively prevented neuronal loss and improved myelination and white matter integrity.

\section{DISCUSSION}

Perinatal H/I-induced brain injury is the major cause of death and long-term neurological impairments [37]. The pathogenesis of $\mathrm{H} / \mathrm{I}$-induced brain injury involves several mechanisms- including, neuroinflammation, oxidative stress and apoptosis [13,18,38]. Lack of effective treatment strategies makes the identification of novel compounds inevitable. The present research was aimed to study the effects of systemic administration of paeoniflorin in 

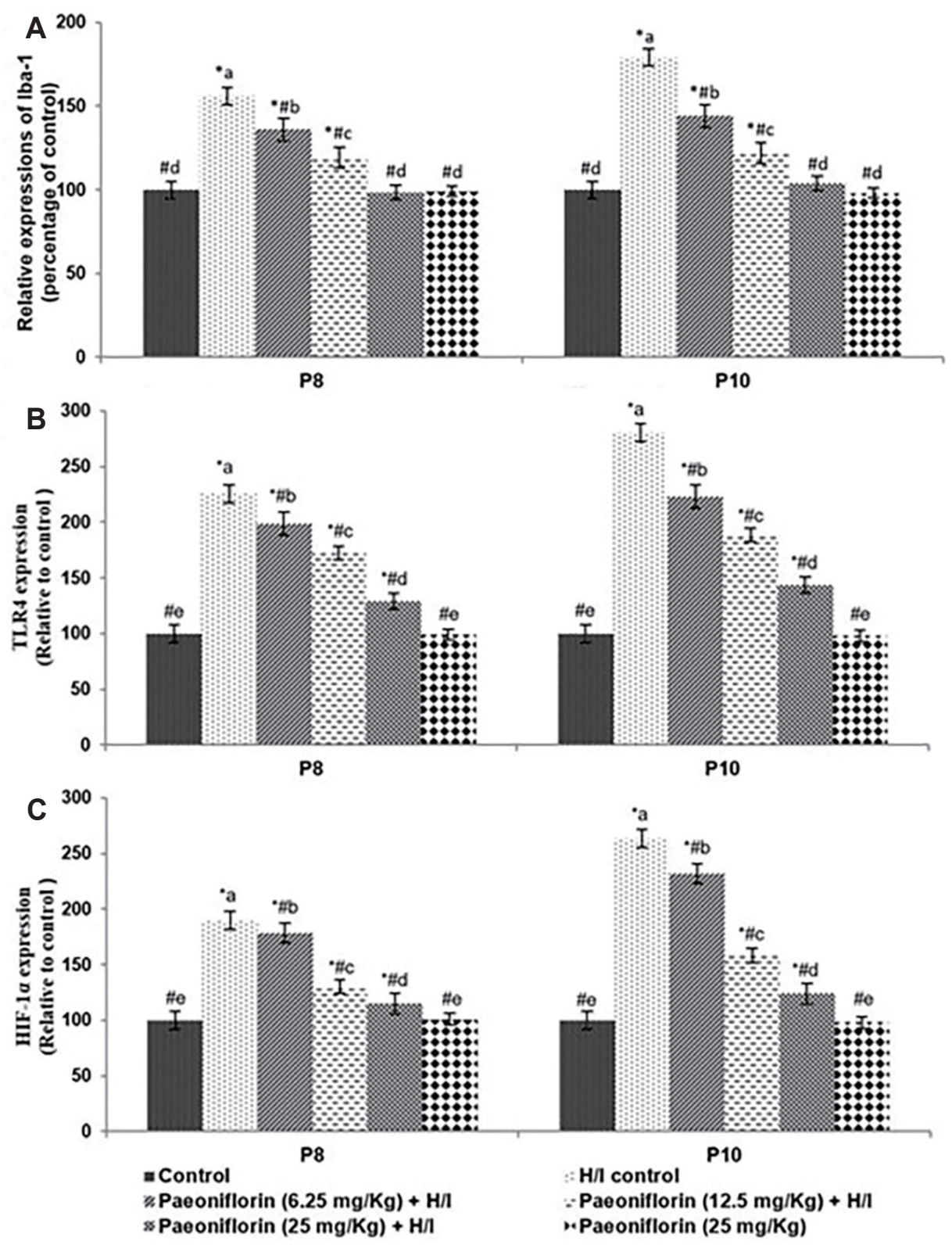

Fig. 6. Paeoniflorin reduced microglial activation. Paeoniflorin reduced lba1 expression (A) microglial activation TLR4 (B) and also reduced microglial activation HIF-1 $\alpha$ (C). Values are represented as mean \pm standard deviation, $n=6$. $p$ $<0.05$ as determined by one-way ANOVA followed by DMRT analysis. Iba-1, ionized calcium binding adaptor molecule 1 ; HIF$1 \alpha$, hypoxia-inducible factor- 1 alpha; $\mathrm{H} /$ I, hypoxia/ischemia; P, postpartum day. *Represents $p<0.05$ vs. control; "represents $\mathrm{p}<0.05$ vs. $\mathrm{H} / \mathrm{I}$ control. ${ }^{\mathrm{a}-\mathrm{e}}$ Represents mean values from different experimental groups that differ from each other at $\mathrm{p}<$ 0.05 .

animal model of neonatal $\mathrm{H} / \mathrm{I}$ brain injury.

Paeoniflorin administered from P3 was found to effectively improve neurobehavioral scores and reduce neuronal apoptosis and infarct volume. Immunoblotting analysis revealed that paeoniflorin significantly down-regulated expression of cleaved caspase-3, chief marker of apoptotic cell death and pro-apoptotic protein, Bad. Interestingly paeoniflorin enhanced expression of antiapoptotic protein, Bcl-2. The balance between anti-apoptotic and pro-apoptotic proteins is crucial in regulating cell existence [39]. The up-regulated Bcl-2 expression by paeoniflorin was noticed to be in line with decreased TUNEL positive cell counts, reflecting the anti-apoptotic effects of paeoniflorin.

Oxidative stress is well documented as a major contributor of H/I-induced brain injury [38]. Raised levels of free radicals including ROS are seen during the 2nd phase of $\mathrm{H} / \mathrm{I}$ brain injury that occurs between 6-48 h of H/I insult. These elevated ROS levels extent for days post H/I insult contributing to further complications as chronic neuroinflammation, decreased neurogenesis and cell death $[35,38]$. In line with the previous reports, increased ROS production and MDA levels were observed in our study reflecting oxidative stress following $\mathrm{H} / \mathrm{I}$ at $24 \mathrm{~h}$ and $72 \mathrm{~h}$. Supressed GSH levels suggest utilisation of antioxidant defences in responses to stress. Paeoniflorin supplementation prior to H/I insult and post insult was found to remarkably reduce ROS production and MDA content and as well increased GSH levels. The observations suggest the anti-oxidant efficacy of paeoniflorin.

Neuroinflammatory processes are pivotal players in the loss of OPCs, loss of white matter integrity and subsequently causing brain injury [40,41]. Microglial cells are primary immune cells in neuroinflammatory responses and are reported to be critically involved in hypoxia-induced neuronal loss $[17,42,43]$. The Tolllike receptors (TLRs) are involved in innate defence responses 

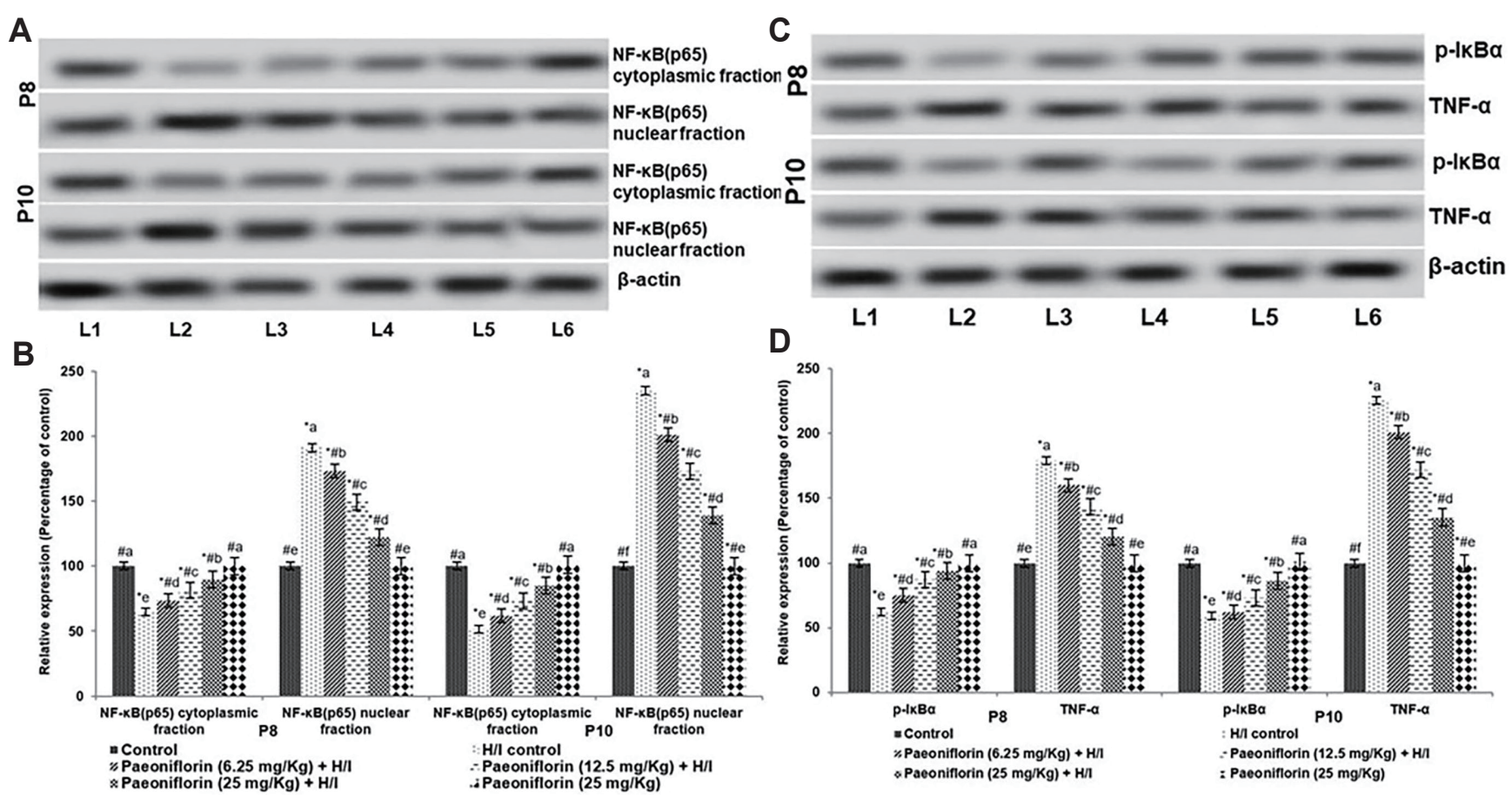

Fig. 7. Paeoniflorin regulated the expression of NF-KB following hypoxic ischemia. Values are represented as mean \pm standard deviation, $n=6 . p$ $<0.05$ as determined by one-way ANOVA followed by DMRT analysis. TNF- $\alpha$, tumor necrosis factor- $\alpha$; H/l, hypoxia/ischemia; P, postpartum day. ${ }^{*}$ Represents $p<0.05$ vs. control; ${ }^{*}$ represents $p<0.05$ vs. $\mathrm{H} / \mathrm{l}$ control. ${ }^{\mathrm{a}-\mathrm{e}}$ Represents mean values from different experimental groups that differ from each other at $\mathrm{p}<0.05$ (L1, control; L2, H/l control; L3, paeoniflorin [6.25 mg/kg] + H/l; L4, paeoniflorin (12.5 mg/kg) + H/l; L5, paeoniflorin (25 mg/kg) + H/l; L6, paeoniflorin ( $25 \mathrm{mg} / \mathrm{kg}]$ ).

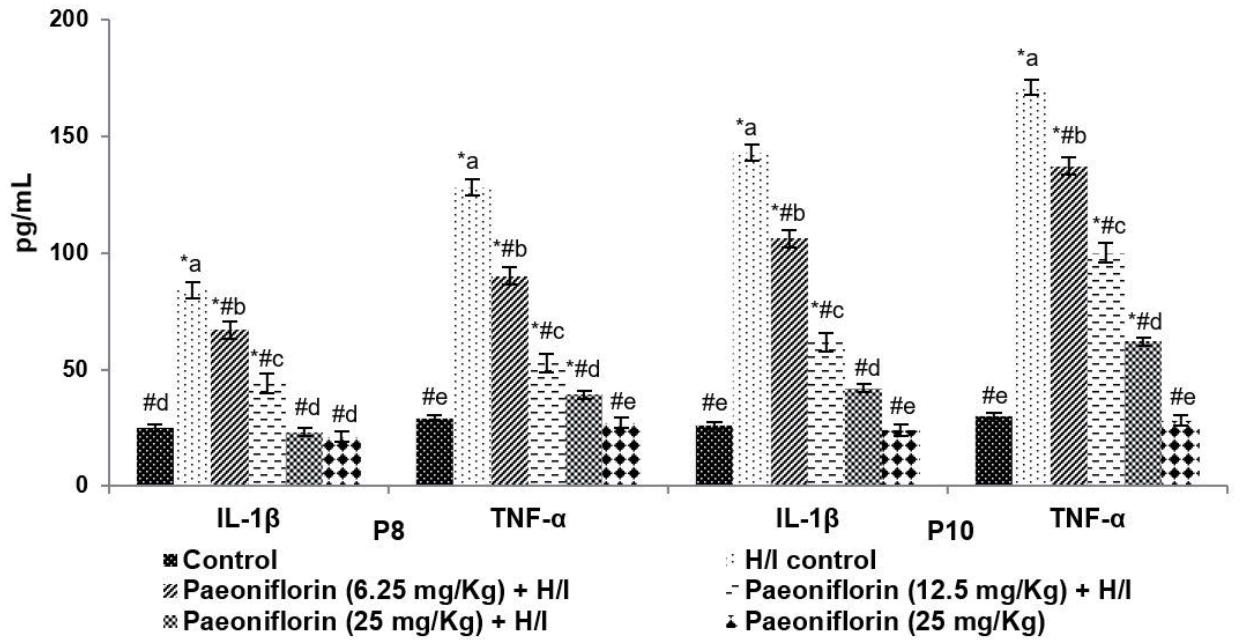

Fig. 8. Paeoniflorin reduced the levels of inflammatory cytokines. Values are represented as mean \pm standard deviation, $n=6 . p<0.05$ as determined by one-way ANOVA followed by DMRT analysis. IL-1 $\beta$, interleukin-1 $\beta$; TNF- $\alpha$, tumor necrosis factor- $\alpha ; H /$, hypoxia/ ischemia; $P$, postpartum day. *Represents $\mathrm{p}<0.05$ vs. control; ${ }^{*}$ represents $\mathrm{p}<0.05$ vs. $\mathrm{H} / \mathrm{I}$ control. ${ }^{\text {aee }}$ Represents mean values from different experimental groups that differ from each other at $p<0.05$. and TLR4 expressed on microglia are reported in several neuroinflammatory diseases $[16,23]$. TLR4 expression was up-regulated following ethanol induced activation of microglia [44]. In our study we noticed marked activation of microglia at $24 \mathrm{~h}$ and at 72 $\mathrm{h}$ following $\mathrm{H} / \mathrm{I}$ insult as evidenced by significantly raised levels of the microglial/macrophage marker, Iba-1. In line with expression levels of Iba-1, TLR4 expression was noticed to be up-regulated.

It is known under that the expression of HIF-1 $\alpha$ is strongly upregulated under hypoxia $[45,46]$. HIF- $1 \alpha$ is found to regulate TLR4 expression in microglia and macrophages under hypoxia $[21,47]$. Here again, we noticed up-regulated expression of HIF-1 $\alpha$ following hypoxic insult. The elevated TLR4 expression may be due to enhanced HIF-1 $\alpha$.

Interestingly, we noted $\mathrm{NF}-\kappa \mathrm{B}$ signaling was significantly up-regulated following $\mathrm{H} / \mathrm{I}$ induction. The results of our study revealed marked nuclear translocation of $\mathrm{NF}_{-} \kappa \mathrm{B}$ (p65) post $\mathrm{H} / \mathrm{I}$. Murugan et al. [36] have reported that hypoxia causes degradation of $\mathrm{p}-\mathrm{I}_{\kappa} \mathrm{B}$ and induces activation of $\mathrm{NF}-\kappa \mathrm{B}$ signaling by promoting translocation of $\mathrm{NF}-\kappa \mathrm{B}$ (p65) to the nucleus. NF- $\kappa \mathrm{B}$ signaling is one the major pathways involved in neuroinflammatory responses leading to expression of pro-inflammatory mediators including cytokines $[48,49]$. NF- $\kappa \mathrm{B}$ activation is found to be 

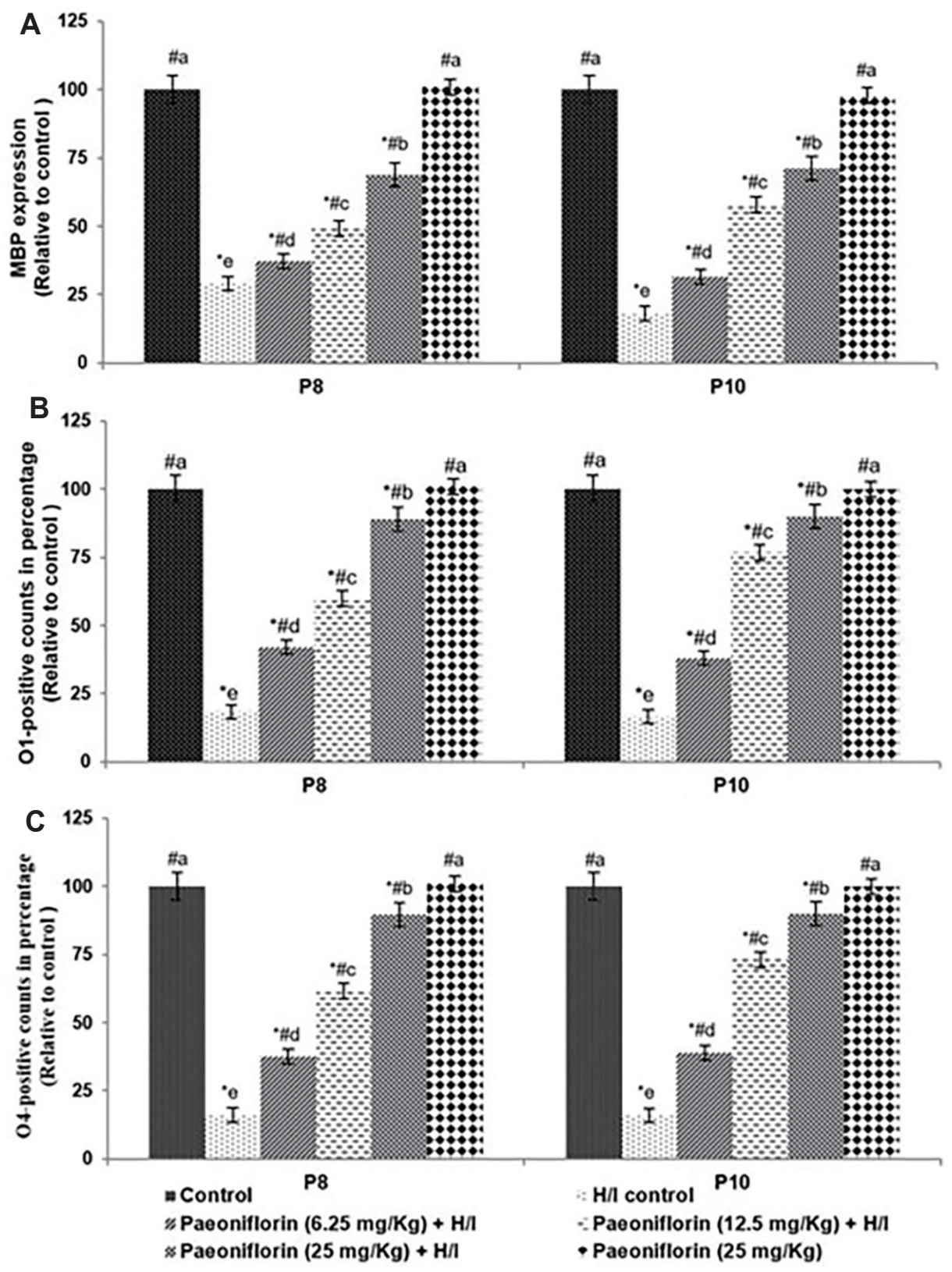

Fig. 9. Paeoniflorin improved MBP levels (A), 01 levels (B), and also 04 levels (C). Values are represented as mean \pm standard deviation, $n=6 . p<0.05$ as determined by one-way ANOVA followed by DMRT analysis. MBP, myelin binding protein; O, oligodendrocytes; $\mathrm{H} / \mathrm{I}$, hypoxia/ischemia; $\mathrm{P}$, postpartum day. *Represents $\mathrm{p}<0.05$ vs. control; " represents $\mathrm{p}<0.05$ vs. $\mathrm{H} / \mathrm{I}$ control. ${ }^{\mathrm{a} e}$ Represents mean values from different experimental groups that differ from each other at $p<$ 0.05 . critically involved in microglial TLR4 signaling. TLR4 has been reported to promote the production of inflammatory mediators through NF- $\kappa \mathrm{B}$ signaling [47]. Increased levels of inflammatory cytokines and enhanced iNOS levels have been reported following $\mathrm{NF}_{-} \kappa \mathrm{B}$ activation in microglia following hypoxic insult [50]. As demonstrated in earlier studies [20,47] significantly elevated levels of TNF- $\alpha$ and IL-1 $\beta$ in the brain tissues of pups exposed to $\mathrm{H} / \mathrm{I}$ insult were noticed. The increased levels reflected activation of NF- $\kappa \mathrm{B} / \mathrm{TLR} 4$ signaling.

It has been suggested that microglial activation and TLR4/ $\mathrm{NF}-\kappa \mathrm{B}$-mediated release of inflammatory mediators induce disruption of white matter integrity and subsequently leading to white matter injury [44]. Pro-inflammatory cytokines were found to cause loss of immature OPCs and affect myelination post H/I insult $[19,26]$. Disruption of myelination occurs due to loss of premyelinating oligodendrocytes and loss of maturation of OPCs [51,52]. OPCs of the immature brain are reported to be specifically vulnerable to $\mathrm{H} / \mathrm{I}$ insults $[11,12]$. Low innate antioxidant enzymes in part have reported to contribute to cell death $[12,15]$. White matter injury is known as a major cause of chronic neurological deficits in H/I survivors [7]. The progenitor cells are pivotal for the replacing the degenerating premyelinated oligodendrocytes and as well in the formation of new myelin. In the present study we noticed significantly reduced MBP expression following H/I insult. Reduced MBP levels are regarded as a marker for white matter injury [53,54]. Similar to the observations of the previous reports, in the present study, marked losses of O4- and O1-positive oligodendrocytes were noticed in P8 and in P10 rat pups that were subjected to $\mathrm{H} / \mathrm{I}$ insult on $\mathrm{P} 7[11,18,20]$.

Paeoniflorin supplementation to the pups prior H/I induc- 
tion significantly reduced microglial activation as evidenced by decreased Iba1 levels and reduced TLR4 expression. Paeoniflorin down-regulated NF- $\kappa \mathrm{B}$ activation in a dose-dependent manner, with $25 \mathrm{mg}$ dose exhibiting higher effects. TNF- $\alpha$ and IL-1 $\beta$ levels were also reduced in the brain tissues suggesting suppression of inflammatory responses. Also, paeoniflorin significantly prevented the loss of O4- and O1-positive oligodendrocytes and improved MBP cell counts in comparison to H/I control group. These observations indicate paeoniflorin prevented white matter injury and improved myelination. Restoration of white matter integrity leads to functional recovery [9]. Thus, paeoniflorin could also aid in neurofunctional improvements post H/I insult. Paeoniflorin significantly reduced oxidative stress and caused downregulation of HIF-1 $\alpha$. Paeoniflorin-mediated reduction in HIF$1 \alpha$ expression could have partly caused downregulation of TLR4 and thus leading to inhibition of TRL4/NF- $\mathrm{B}$ signaling. Downregulated NF- $\mathrm{KB}$ signaling and inflammatory cytokines by paeoniflorin could have aided in prevention of neuronal loss and white matter injury. The results demonstrate the neuroprotective efficiency of paeoniflorin.

Paeoniflorin pre-treatment significantly attenuated oxidative stress and inhibited up-regulation of TLR4/NF- $\mathrm{KB}$ mediated inflammatory responses. Paeoniflorin markedly reduced neuronal loss and white matter injury by improving MBP-positive counts and O4- and O1-positive oligodendrocytes. Our results suggest that paeoniflorin as a potent candidate in therapy of $\mathrm{H} / \mathrm{I}$ induced neurological impairments.

\section{CONFLICTS OF INTEREST}

The authors declare no conflicts of interest.

\section{SUPPLEMENTARY MATERIALS}

Supplementary data including one figure can be found with this article online at https://doi.org/10.4196/kjpp.2021.25.2.97.

\section{REFERENCES}

1. de Haan M, Wyatt JS, Roth S, Vargha-Khadem F, Gadian D, Mishkin M. Brain and cognitive-behavioural development after asphyxia at term birth. Dev Sci. 2006;9:350-358.

2. Hamrick SE, Ferriero DM. The injury response in the term newborn brain: can we neuroprotect? Curr Opin Neurol. 2003;16:147154.

3. Edwards AD, Brocklehurst P, Gunn AJ, Halliday H, Juszczak E, Levene M, Strohm B, Thoresen M, Whitelaw A, Azzopardi D. Neurological outcomes at 18 months of age after moderate hypothermia for perinatal hypoxic ischaemic encephalopathy: synthesis and meta-analysis of trial data. BMJ. 2010;340:c363.
4. Anderson P, Doyle LW. Neurobehavioral outcomes of school-age children born extremely low birth weight or very preterm in the 1990s. JAMA. 2003;289:3264-3272.

5. Hack M, Youngstrom EA, Cartar L, Schluchter M, Taylor HG, Flannery D, Klein N, Borawski E. Behavioral outcomes and evidence of psychopathology among very low birth weight infants at age 20 years. Pediatrics. 2004;114:932-940.

6. Damodaran T, Hassan Z, Navaratnam V, Muzaimi M, Ng G, Müller CP, Liao P, Dringenberg HC. Time course of motor and cognitive functions after chronic cerebral ischemia in rats. Behav Brain Res. 2014;275:252-258.

7. Back SA. Cerebral white and gray matter injury in newborns: new insights into pathophysiology and management. Clin Perinatol. 2014;41:1-24.

8. Huria T, Beeraka NM, Al-Ghamdi B, Fern R. Premyelinated central axons express neurotoxic NMDA receptors: relevance to early developing white-matter injury. J Cereb Blood Flow Metab. 2015;35:543553.

9. Murray AL, Thompson DK, Pascoe L, Leemans A, Inder TE, Doyle LW, Anderson JFI, Anderson PJ. White matter abnormalities and impaired attention abilities in children born very preterm. Neuroimage. 2016;124(Pt A):75-84.

10. Song FE, Huang JL, Lin SH, Wang S, Ma GF, Tong XP. Roles of NG2-glia in ischemic stroke. CNS Neurosci Ther. 2017;23:547-553.

11. Back SA, Luo NL, Borenstein NS, Levine JM, Volpe JJ, Kinney HC. Late oligodendrocyte progenitors coincide with the developmental window of vulnerability for human perinatal white matter injury. $J$ Neurosci. 2001;21:1302-1312.

12. Back SA, Riddle A, McClure MM. Maturation-dependent vulnerability of perinatal white matter in premature birth. Stroke. 2007;38(2 Suppl):724-730.

13. McQuillen PS, Ferriero DM. Selective vulnerability in the developing central nervous system. Pediatr Neurol. 2004;30:227-235.

14. McLean C, Ferriero D. Mechanisms of hypoxic-ischemic injury in the term infant. Semin Perinatol. 2004;28:425-432.

15. Thorburne SK, Juurlink BH. Low glutathione and high iron govern the susceptibility of oligodendroglial precursors to oxidative stress. $J$ Neurochem. 1996;67:1014-1022.

16. Kadhim H, Tabarki B, De Prez C, Rona AM, Sébire G. Interleukin-2 in the pathogenesis of perinatal white matter damage. Neurology. 2002;58:1125-1128.

17. Kaur C, Ling EA. Periventricular white matter damage in the hypoxic neonatal brain: role of microglial cells. Prog Neurobiol. 2009; 87:264-280.

18. Cai Z, Lin S, Fan LW, Pang Y, Rhodes PG. Minocycline alleviates hypoxic-ischemic injury to developing oligodendrocytes in the neonatal rat brain. Neuroscience. 2006;137:425-435.

19. Fan LW, Lin S, Pang Y, Rhodes PG, Cai Z. Minocycline attenuates hypoxia-ischemia-induced neurological dysfunction and brain injury in the juvenile rat. Eur J Neurosci. 2006;24:341-350.

20. Carty ML, Wixey JA, Colditz PB, Buller KM. Post-insult minocycline treatment attenuates hypoxia-ischemia-induced neuroinflammation and white matter injury in the neonatal rat: a comparison of two different dose regimens. Int J Dev Neurosci. 2008;26:477-485.

21. Ock J, Jeong J, Choi WS, Lee WH, Kim SH, Kim IK, Suk K. Regulation of Toll-like receptor 4 expression and its signaling by hypoxia in cultured microglia. J Neurosci Res. 2007;85:1989-1995. 
22. Kim SY, Choi YJ, Joung SM, Lee BH, Jung YS, Lee JY. Hypoxic stress up-regulates the expression of Toll-like receptor 4 in macrophages via hypoxia-inducible factor. Immunology. 2010;129:516-524.

23. Lehnardt S, Massillon L, Follett P, Jensen FE, Ratan R, Rosenberg PA, Volpe JJ, Vartanian T. Activation of innate immunity in the CNS triggers neurodegeneration through a Toll-like receptor 4-dependent pathway. Proc Natl Acad Sci U S A. 2003;100:8514-8519.

24. Kadhim H, Tabarki B, Verellen G, De Prez C, Rona AM, Sébire G. Inflammatory cytokines in the pathogenesis of periventricular leukomalacia. Neurology. 2001;56:1278-1284.

25. Silveira RC, Procianoy RS. Interleukin-6 and tumor necrosis factoralpha levels in plasma and cerebrospinal fluid of term newborn infants with hypoxic-ischemic encephalopathy. J Pediatr. 2003;143: 625-629.

26. Cai Z, Lin S, Pang Y, Rhodes PG. Brain injury induced by intracerebral injection of interleukin-1beta and tumor necrosis factor-alpha in the neonatal rat. Pediatr Res. 2004;56:377-384.

27. Liu DF, Wei W, Song LH. Protective effect of paeoniflorin on immunological liver injury induced by bacillus Calmette-Guerin plus lipopolysaccharide: modulation of tumour necrosis factor-alpha and interleukin-6 MRNA. Clin Exp Pharmacol Physiol. 2006;33:332339.

28. Zhong SZ, Ge QH, Li Q, Qu R, Ma SP. Peoniflorin attentuates Abeta((1-42))-mediated neurotoxicity by regulating calcium homeostasis and ameliorating oxidative stress in hippocampus of rats. $J$ Neurol Sci. 2009;280:71-78.

29. Zhou H, Bian D, Jiao X, Wei Z, Zhang H, Xia Y, He Y, Dai Y. Paeoniflorin protects against lipopolysaccharide-induced acute lung injury in mice by alleviating inflammatory cell infiltration and microvascular permeability. Inflamm Res. 2011;60:981-990.

30. Wang Z, Liu Z, Yu G, Nie X, Jia W, Liu RE, Xu R. Paeoniflorin inhibits migration and invasion of human glioblastoma cells via suppression transforming growth factor $\beta$-induced epithelialmesenchymal transition. Neurochem Res. 2018;43:760-774.

31. Garber JC. Committee for the update of the guide for the care and use of laboratory animals. In: Committee for the Update of the Guide for the Care and Use of Laboratory Animals, Institute for Laboratory Animal Research, Division on Earth and Life Studies, National Research Council of the National Academies, editors. Guide for the care and use of laboratory animals. 8th ed. Washington, D.C.: National Academies Press; 2011.

32. Rice JE 3rd, Vannucci RC, Brierley JB. The influence of immaturity on hypoxic-ischemic brain damage in the rat. Ann Neurol. 1981;9:131-141.

33. Longa EZ, Weinstein PR, Carlson S, Cummins R. Reversible middle cerebral artery occlusion without craniectomy in rats. Stroke. 1989; 20:84-91.

34. Garcia JH, Wagner S, Liu KF, Hu XJ. Neurological deficit and extent of neuronal necrosis attributable to middle cerebral artery occlusion in rats. Statistical validation. Stroke. 1995;26:627-634; discussion 635.

35. Arteaga O, Álvarez A, Revuelta M, Santaolalla F, Urtasun A, Hilario E. Role of antioxidants in neonatal hypoxic-ischemic brain injury: new therapeutic approaches. Int J Mol Sci. 2017;18:265.

36. Murugan M, Sivakumar V, Lu J, Ling EA, Kaur C. Expression of Nmethyl D-aspartate receptor subunits in amoeboid microglia mediates production of nitric oxide via NF- $\kappa$ B signaling pathway and oligodendrocyte cell death in hypoxic postnatal rats. Glia. 2011;59:521-539.
37. Graham EM, Ruis KA, Hartman AL, Northington FJ, Fox HE. A systematic review of the role of intrapartum hypoxia-ischemia in the causation of neonatal encephalopathy. Am J Obstet Gynecol. 2008;199:587-595.

38. Arteaga O, Revuelta M, Urigüen L, Álvarez A, Montalvo H, Hilario E. Pretreatment with resveratrol prevents neuronal injury and cognitive deficits induced by perinatal hypoxia-ischemia in rats. PLoS One. 2015;10:e0142424.

39. Zhao H, Yenari MA, Cheng D, Sapolsky RM, Steinberg GK. Bcl-2 overexpression protects against neuron loss within the ischemic margin following experimental stroke and inhibits cytochrome $\mathrm{c}$ translocation and caspase-3 activity. J Neurochem. 2003;85:1026-1036.

40. Qiu L, Zhu C, Wang X, Xu F, Eriksson PS, Nilsson M, Cooper-Kuhn CM, Kuhn HG, Blomgren K. Less neurogenesis and inflammation in the immature than in the juvenile brain after cerebral hypoxiaischemia. J Cereb Blood Flow Metab. 2007;27:785-794.

41. Wang X, Stridh L, Li W, Dean J, Elmgren A, Gan L, Eriksson K, Hagberg H, Mallard C. Lipopolysaccharide sensitizes neonatal hypoxic-ischemic brain injury in a MyD88-dependent manner. $J$ Immunol. 2009;183:7471-7477.

42. Kaur C, You Y. Ultrastructure and function of the amoeboid microglial cells in the periventricular white matter in postnatal rat brain following a hypoxic exposure. Neurosci Lett. 2000;290:17-20.

43. Cunningham C. Microglia and neurodegeneration: the role of systemic inflammation. Glia. 2013;61:71-90.

44. Fernandez-Lizarbe S, Pascual M, Guerri C. Critical role of TLR4 response in the activation of microglia induced by ethanol. J Immunol. 2009;183:4733-4744.

45. Semenza GL. Targeting HIF-1 for cancer therapy. Nat Rev Cancer. 2003;3:721-732.

46. Pugh CW, Ratcliffe PJ. Regulation of angiogenesis by hypoxia: role of the HIF system. Nat Med. 2003;9:677-684.

47. Yao L, Kan EM, Lu J, Hao A, Dheen ST, Kaur C, Ling EA. Toll-like receptor 4 mediates microglial activation and production of inflammatory mediators in neonatal rat brain following hypoxia: role of TLR4 in hypoxic microglia. J Neuroinflammation. 2013;10:23.

48. Li Q, Verma IM. NF-kappaB regulation in the immune system. Nat Rev Immunol. 2002;2:725-734.

49. Shen W, Zhang C, Zhang G. Nuclear factor kappaB activation is mediated by NMDA and non-NMDA receptor and L-type voltagegated $\mathrm{Ca}^{2+}$ channel following severe global ischemia in rat hippocampus. Brain Res. 2002;933:23-30.

50. Bianchi R, Giambanco I, Donato R. S100B/RAGE-dependent activation of microglia via NF-kappaB and AP-1 Co-regulation of COX2 expression by S100B, IL-1beta and TNF-alpha. Neurobiol Aging. 2010;31:665-677.

51. Back SA, Rosenberg PA. Pathophysiology of glia in perinatal white matter injury. Glia. 2014;62:1790-1815.

52. Segovia KN, McClure M, Moravec M, Luo NL, Wan Y, Gong X, Riddle A, Craig A, Struve J, Sherman LS, Back SA. Arrested oligodendrocyte lineage maturation in chronic perinatal white matter injury. Ann Neurol. 2008;63:520-530.

53. Inder TE, Volpe JJ. Mechanisms of perinatal brain injury. Semin Neonatol. 2000;5:3-16.

54. Wang X, Hagberg H, Zhu C, Jacobsson B, Mallard C. Effects of intrauterine inflammation on the developing mouse brain. Brain Res. 2007;1144:180-185. 